\title{
Helping Haiti
}

Previously published at www.cmaj.ca

$\mathrm{T}$ he earthquakes devastating Haiti are an unpredictable but probably inevitable geological upheaval; however, the deaths, suffering and social misery that follow are not. Like a nightmare, we witness another disaster there, begin to prop the country up and prepare to wait for the next catastrophe.

Haiti appears to be receiving what it needs now. In fact, the speed and scale of the disaster relief are remarkable. But once the dust has settled, the dead are buried and the wounded are treated, what Haiti needs next is less apparent to the people who are not already engaged there. To ensure survival, rudimentary health care, food, clothing and more durable shelter are obvious. Then the focus will turn to hospitals, schools, roads and communications networks.

Sadly, if Haiti's past 200 years are any guide, few — if any - of these things will materialize. From the Spanish conquest and depopulation of the island of Hispaniola to the French occupation and deforestation of its western third (Haiti), from the slave rebellions to independence, to successive American interventions and a series of corrupt and typically brutal governments, Haiti has been robbed of its chance to bloom.

Haiti's soil, exposed by extreme deforestation, is now leached by tropical rain, bleached by equatorial ozone and exhausted by overfarming of sugar cane. Abundant rains have nowhere to go but into the Caribbean Sea, taking the soil with it. Clean water, safe sewage disposal and adequate food are precarious every day. Before the earthquakes began, basic medical care and control of communicable disease were mere dreams for most people. So, although meeting the country's immediate needs might follow the relief effort, it will not be enough.

This country of nine million, proud of its history as the $\vec{I}$ first black republic in the world, needs help at a more fundamental and sustained level. It needs forests replanted, so clean water can be retained in the soil and seep to the aquifers; so sand will turn again to soil, and so its people will have a sustainable source of wood. It needs to rebuild a farm economy to produce food for its people and cash crops that can be sold internationally at a fair price.
Before colleges and universities, it needs primary and secondary education for every child. Before big city hospitals and tertiary care, it needs clinics in towns and villages staffed by front-line health care workers who have basic supplies and equipment so that infants can survive, children can grow and adults can work.

This catastrophe, which has destroyed so much of the social structure, can give Haitians the chance to rebuild their country in more effective and durable ways. As a precondition to success, they will need to build a stable government that has the best interests of Haiti's large, poor majority constantly in mind.

And if the rest of the world is to achieve more for Haitians than repeating past miseries, a partnership is needed between Haiti, foreign governments and aid groups that is deeper and more constant, oriented toward rebuilding the land, the farms, the health care system and the people. A more modern economy, with well-built towns and cities, will follow once a basis for life and growth is restored to its people. To do what Haiti needs, nations will have to act together with her over the long haul with cash, expertise and sweat — no strings attached.

Pope John Paul II got it right on his visit to Haiti in 1983 when he proclaimed, mere metres from then-dictator JeanClaude (Baby Doc) Duvalier: "Something has to change here!" Perhaps even he did not realize at the time that the "here" referred not only to Haiti, but also to the rest of the world that brought Haiti to the brink.

\section{Ken Flegel MDCM MSc}

Senior Associate Editor

Paul C. Hébert MD MHSc

Editor-in-Chief

CMAJ

Editorial advisory team: Noni MacDonald MD MSc, Matthew B. Stanbrook MD PhD

and Joan Ramsay BA

Competing interests: See www.cmaj.ca/misc/edboard.shtml

CMAJ 2010. DOI:10.1503/cmaj.100121 